\title{
Gender-based differences in physician payments within the fee-for-service system in Ontario: a retrospective, cross-sectional study
}

\author{
Zamir Merali MD, Armaan K. Malhotra MD, Michael Balas BHSc, Gianni R. Lorello BSc MD MSc, Alana Flexman MD, \\ Tara Kiran MD MSc, Christopher D. Witiw MD MSc
}

Cite as: CMAJ 2021 October 18;193:E1584-91. doi: 10.1503/cmaj.210437

\begin{abstract}
Background: Differences in physician income by gender have been described in numerous jurisdictions, but few studies have looked at a Canadian cohort with adjustment for confounders. In this study, we aimed to understand differences in fee-for-service payments to men and women physicians in Ontario.
\end{abstract}

Methods: We conducted a cross-sectional analysis of all Ontario physicians who submitted claims to the Ontario Health Insurance Plan (OHIP) in 2017. For each physician, we gathered demographic information from the College of Phys- icians and Surgeons of Ontario registry. We compared differences in physician claims between men and women in the entire cohort and within each specialty using multivariable linear regressions, controlling for length of practice, specialty and practice location.

Results: We identified a cohort of 30167 physicians who submitted claims to OHIP in 2017, including 17992 men and 12175 women. When controlling for confounding variables in a linear mixedeffects regression model, annual physician claims were $\$ 93930$ (95\% confi- dence interval \$88434 to \$99431) higher for men than for women. Women claimed $74 \%$ as much as men when adjusting for covariates. This discrepancy was present in nearly all specialty categories. Men claimed more than women throughout their careers, with the greatest gap 10-15 years into practice.

Interpretation: We found a gender gap in fee-for-service claims in Ontario, with women claiming less than men overall and in nearly every specialty. Further work is required to understand the root causes of the gender pay gap.
A gender pay gap in physician incomes has been described across numerous jurisdictions. ${ }^{1}$ Previous analyses have found income differences between women and men in the general physician population, among academic physicians and among physicians within the same specialty, ${ }^{2-8}$ and when controlling for years of experience, hours worked, geographic location, race and practice type..$^{9-13}$

Although the difference in physician income between women and men is well described in the United States, fewer studies have looked at a Canadian cohort. An analysis of surgeons in Ontario found that female surgeons earned less per hour spent operating than male surgeons, and suggested that female physicians were more likely to perform less lucrative procedures than male physicians. ${ }^{14} \mathrm{~A}$ recent report released by the Ontario Medical Association highlighted income disparity between men and women physicians in Ontario, but did not provide a detailed breakdown by specialty. ${ }^{15}$ Transparent and detailed reporting on gender differences in physician payments can provide data to guide advocacy for greater pay equity.

In this study, we aimed to describe payments to physicians across the province of Ontario by gender when controlling for specialty choice, career stage and physician demographics.

\section{Methods}

\section{Context}

Ontario has a publicly funded, single-payer health care system for physician services. About $70 \%$ of physician payments are paid through a fee-for-service model for claims to the Ontario Health Insurance Plan (OHIP). The remainder of physician payments come from alternative payment plans, which can consist of salaries, hourly rates, capitation models or contract-based payments. ${ }^{16}$ A physician's salary can comprise a combination of 
payments through fee-for-service and alternative payment plans. In particular, family physicians are more likely to be remunerated through an alternative payment plan than other physicians. ${ }^{16}$

\section{Data sources}

We collected data on physician payments and demographics from 4 publicly available sources. We obtained physician-level data on fee-for-service claims to OHIP in 2017, which were made public after a freedom of information request in $2018,{ }^{17}$ and demographic information from the College of Physicians and Surgeons of Ontario (CPSO) registry, which is also publicly available. ${ }^{18}$ We collected aggregate data on total physician payments in 2017 from the National Physician Database. ${ }^{19}$ The National Physician Database is maintained by the Canadian Institute of Health Information and contains accurate demographic information on practising physicians in Ontario. We also gathered aggregate data on the number of physicians practising in Ontario in 2017 from the Ontario Physician Human Resources Data Centre (OPHRDC). The OPHRDC is considered the definitive registry of physicians in practice in Ontario.

\section{Study design}

We conducted a cross-sectional analysis of physician payments from OHIP during 2017. We used a unique identifier for each physician (CPSO number) and obtained demographic information from the CPSO registry, including self-reported gender, ${ }^{20}$ number of years since obtaining an independent practice licence, location of practice (including the forward sortation area of the postal code), number of languages spoken, specialty and medical school. We derived whether the physician's location of practice was rural or urban from postal codes based on the Canada Post Corporation conventions. ${ }^{21}$ We grouped internal medicine subspecialties with fewer than 300 practitioners (i.e., endocrinology, gastroenterology, geriatrics, hematology, infectious disease, medical oncology, nephrology, respirology, rheumatology) together into an aggregate category to ensure sufficient subjects per covariate, to prevent overfitting in regression models. We used this same threshold to group surgical subspecialties (i.e., cardiac surgery, otolaryngology, plastic surgery, neurosurgery, thoracic surgery, vascular surgery and urology).

The data set used in our primary analysis did not include physicians who were reimbursed entirely under an alternative payment plan. To determine the number of Ontario physicians missing from our data set, we compared it with the aggregate data derived from the OPHRDC for the same study period. ${ }^{22}$

\section{Statistical analysis}

We compared baseline physician characteristics and unadjusted total annual claims between women and men using a standardized mean difference (SMD), as described by Austin. ${ }^{23}$ We considered a value greater than 0.1 as a sign of an important covariate imbalance. ${ }^{23}$

To determine the adjusted association between physician gender and total annual claims, we constructed a linear mixed effects regression, with total annual claims as the outcome and physician specialty as a random effect. Fixed effects included gender, years in practice and rural or urban location of practice. We chose these covariates a priori based on literature review.
Previous studies have found that the magnitude of the gender pay gap increases with time after entering independent practice. ${ }^{24,25}$ We chose to include geographic location in the model because previous studies have found physician compensation to vary between urban and rural areas. ${ }^{26}$ We also conducted prespecified multivariable linear regressions for physicians within each specialty, with gender, years in practice and rural or urban location of practice as covariates. We fitted all regression models using a restricted log-likelihood estimator. We adjusted $p$ values to correct for multiple hypothesis testing using the Holm-Bonferroni method. ${ }^{27}$ We generated estimated marginal salaries stratified by gender from the fitted models. We compared the distribution of women and men in each specialty between the study population and the OPHRDC data using $\chi^{2}$ tests for proportions.

We conducted a sensitivity analysis to test if the results of our primary analysis would change if alternative payment plan remuneration was accounted for. To do this, we used data derived from the 2017 National Physician Database, which includes aggregate total payments to physicians in 19 specialties. ${ }^{19}$ For each specialty, we compared the total physician payments to the fee-forservice billings in our primary analysis. The difference between the 2 values $(\delta)$ gave an estimation of the physician payments within each specialty that were missing from our primary analysis.

First, we considered a scenario in which men and women were equally likely to receive payments through alternative payment plans. Using this assumption, we adjusted the fee-for-service payments to men and women within each specialty upwards by $\delta$. We then compared adjusted physician payments between men and women using a linear mixed effects regression, controlling for location and years of practice. Second, we considered a conservative scenario in which all payments from alternative payment plans had gone to women. We adjusted the payments to women within each specialty upwards and left payments to men unchanged. This assumption would likely underestimate the true difference in payments between men and women, but it could provide a lower bound on the true difference in payments. Using this second assumption, we again compared physician payments to men and women using a linear mixed effects regression, as above.

We used R studio version 1.3 for all statistical analyses. We generated plots using the ggplot2 package.

\section{Ethics approval}

The study was reviewed by the Research Ethics Board (REB) at Unity Health Toronto and deemed not to require REB approval given that data are all publicly available.

\section{Results}

We identified 30167 physicians who had submitted claims to OHIP between Jan. 1, 2017, and Dec. 31, 2017. Of these, 17992 (59.6\%) physicians were men and 12175 (40.4\%) were women. The OPHRDC report identified 30584 practising physicians within Ontario during the same time period. Our data set thus included $98.6 \%$ of the total practising physicians in Ontario during the study period. We evaluated the distribution of physicians within each specialty category in our data set compared with the 
OPHRDC report (59\% men, $41 \%$ women) and found no significant difference in the distribution of men and women physicians (Appendix 1, Table S1, available at www.cmaj.ca/lookup/ doi/10.1503/cmaj.210437/tab-related-content). Although in recent years the CPSO has allowed physicians to identify as nonbinary during registration, no physicians in our data set reported a gender identity other than man or woman.

A comparison of physician characteristics stratified by gender is seen in Table 1. On average, men in our cohort had been in practice longer than women (19.8 v. $14.0 \mathrm{yr}$, SMD 0.44). Pediatrics and obstetrics and gynecology had a lower ratio of men to women, compared with the overall cohort (Table 1). Medical subspecialties, psychiatry and laboratory-based specialties had a similar ratio of women and men as the overall cohort. In the remainder of specialties, the ratio of men to women was higher than in the overall cohort. When grouping physicians by total annual claims, more women were represented in the group of physicians claiming less than $\$ 300000$ annually, and more men were represented among physicians claiming $\$ 300000$ or more annually (Figure 1 ). Density plots of physician payments for women and men showed

Table 1: Characteristics of Ontario physicians in 2017 by gender

\begin{tabular}{|c|c|c|c|c|}
\hline \multirow[b]{2}{*}{ Characteristic } & \multicolumn{3}{|c|}{ No. (\%) of physicians* } & \multirow[b]{2}{*}{ SMD } \\
\hline & $\begin{array}{c}\text { All } \\
n=30167\end{array}$ & $\begin{array}{c}\text { Men } \\
n=17992\end{array}$ & $\begin{array}{c}\text { Women } \\
n=12175\end{array}$ & \\
\hline \multicolumn{5}{|l|}{ Amount claimed, \$ } \\
\hline$<100000$ & 11877 (39.4) & $5985(33.3)$ & $5890(48.4)$ & 0.48 \\
\hline $100000-299999$ & $8898(29.5)$ & $4927(27.4)$ & $3971(32.6)$ & \\
\hline$\geq 300000$ & $9392(31.1)$ & $7080(39.4)$ & $2312(19.0)$ & \\
\hline Years in practice, mean \pm SD & $17.4 \pm 13.8$ & $19.8 \pm 14.5$ & $14.0 \pm 11.7$ & 0.44 \\
\hline \multicolumn{5}{|l|}{ Languages spoken } \\
\hline 1 & $17770(58.9)$ & $10569(58.7)$ & $7201(59.1)$ & 0.03 \\
\hline 2 & $8628(28.6)$ & $5100(28.3)$ & $3528(29.0)$ & \\
\hline 3 & $2583(8.6)$ & $1587(8.8)$ & $996(8.2)$ & \\
\hline$>3$ & $1186(3.9)$ & $736(4.1)$ & $450(3.7)$ & \\
\hline Rural location of practice & $1076(3.6)$ & $614(3.4)$ & $462(3.8)$ & \\
\hline Specialty & & & & 0.51 \\
\hline Anesthesiology & $1379(4.6)$ & $936(5.2)$ & $443(3.6)$ & \\
\hline Cardiology & $641(2.1)$ & $522(2.9)$ & $119(1.0)$ & \\
\hline Clinical immunology & $36(0.1)$ & $21(0.1)$ & $15(0.1)$ & \\
\hline Dermatology & $238(0.8)$ & $124(0.7)$ & $114(0.9)$ & \\
\hline Diagnostic radiology & $1166(3.9)$ & $835(4.6)$ & $331(2.7)$ & \\
\hline Emergency medicine & $255(0.8)$ & $175(1.0)$ & $79(0.6)$ & \\
\hline Family medicine & $14314(47.4)$ & $7675(42.7)$ & $6639(54.5)$ & \\
\hline General surgery & $840(2.8)$ & $618(3.4)$ & $222(1.8)$ & \\
\hline Internal medicine & $1797(6.0)$ & $1236(6.9)$ & $561(4.6)$ & \\
\hline Medical subspecialty & $1730(5.7)$ & $1012(5.6)$ & $718(5.8)$ & \\
\hline Neurology & $422(1.4)$ & $276(1.5)$ & $146(1.2)$ & \\
\hline Obstetrics and gynecology & $918(3.0)$ & $384(2.1)$ & $534(4.4)$ & \\
\hline Ophthalmology & $479(1.6)$ & $375(2.1)$ & $104(0.8)$ & \\
\hline Orthopedic surgery & $650(2.2)$ & $592(3.3)$ & $58(0.5)$ & \\
\hline Pediatrics & $1206(4.0)$ & $504(2.8)$ & $702(5.8)$ & \\
\hline Pathology, microbiology and clinical biochemistry & $308(1.0)$ & $191(1.1)$ & $117(1.0)$ & \\
\hline Physical medicine & $210(0.7)$ & $135(0.8)$ & $75(0.6)$ & \\
\hline Psychiatry & $2188(7.2)$ & $1247(6.9)$ & $941(7.7)$ & \\
\hline Surgical subspecialty & $821(2.7)$ & $667(3.7)$ & $154(1.3)$ & \\
\hline
\end{tabular}



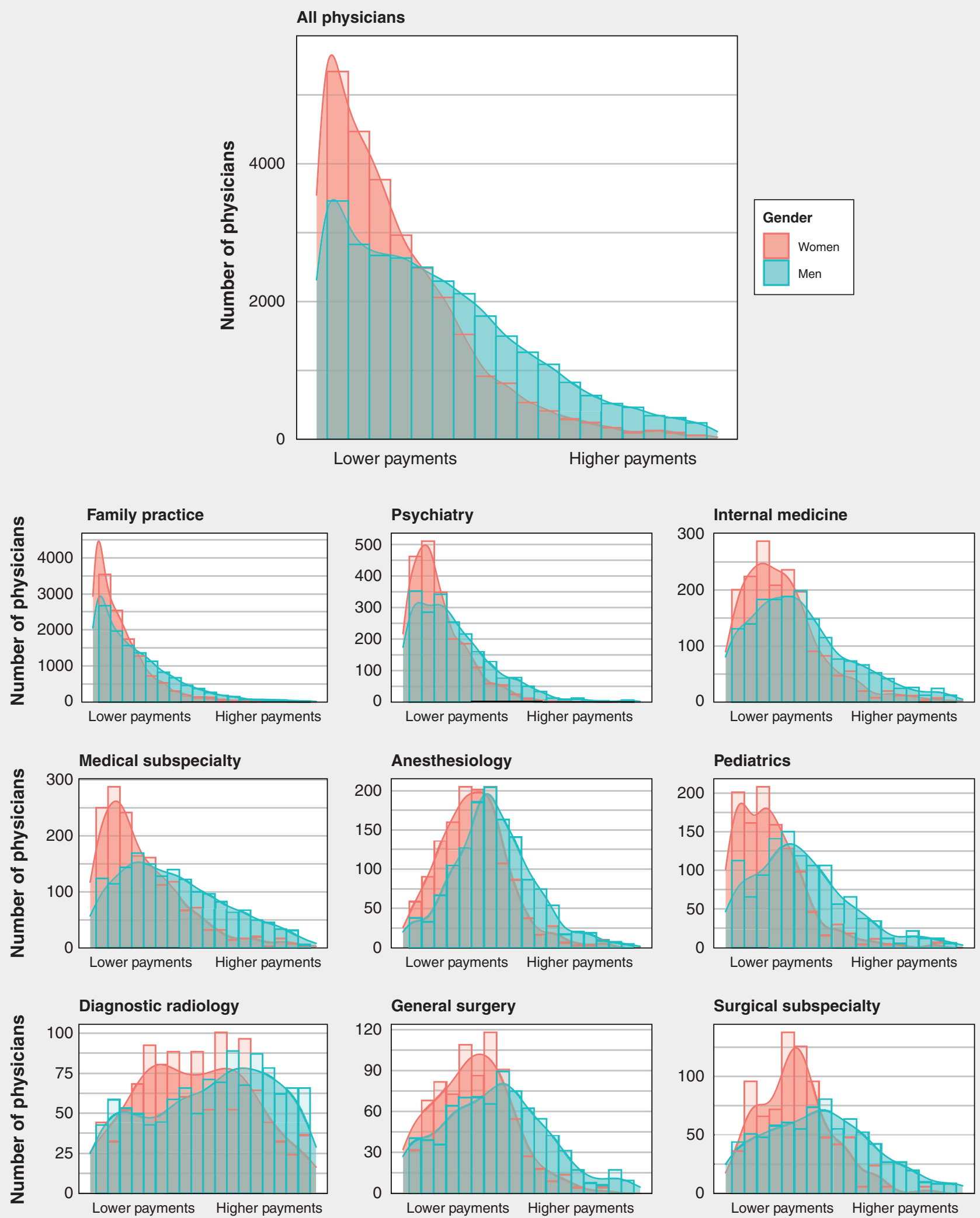

Figure 1: Distribution of physician payments, stratified by gender, for all physicians and for physicians within the 9 most common specialty categories. 
right-skewed distributions in which the highest paid physicians tended to be men. We compared the total annual claims of women and men by length of time in independent practice. Men claimed more than women throughout their careers; the magnitude of difference peaked at 10-15 years into practice (Figure 2).

\section{Multivariable regression}

The unadjusted difference in physician claims between men and women was $\$ 123364$ (95\% confidence interval [Cl] \$117355 to $\$ 129372)$. When adjusting for specialty choice, numbers of years in practice and location of practice, total annual claims were $\$ 93930$ (95\% Cl \$88434 to \$99431) higher for men than for women (Table 2). Estimated mean payments to women were $74 \%$ of estimated payments to men. Urban location of practice was associated with higher total annual claims. Physicians in practice for 11-15 years had the highest total annual claims, and claims decreased with successively higher or lower years in practice (Figure 2).

We explored the difference in fee-for-service claims within each specialty by running a separate linear regression for physicians within each specialty category (Table 3). When adjusting for length of time in practice and rural or urban location of practice, fee-for-service claims were significantly higher for men within each specialty except for emergency medicine.

\section{Sensitivity analysis}

In the sensitivity analysis, we estimated payments from alternative payment plan by specialty. On average, the estimated payments from alternative payment plan for 2017 were $\$ 55623$

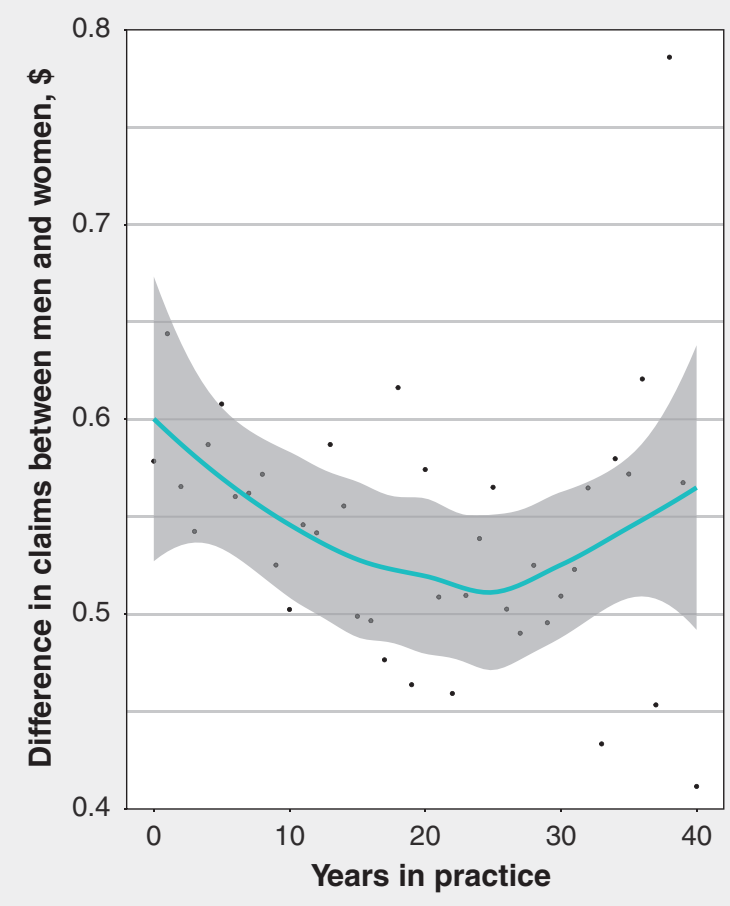

Figure 2: Difference in total annual claims between women and men physicians by number of years in practice. across all specialties (Appendix 2, Table S2, available at www. cmaj.ca/lookup/doi/10.1503/cmaj.210437/tab-related-content). We first supposed that men and women were equally likely to receive payments from alternative payment plans, and adjusted the payments listed by the National Physician Database. In this scenario, physician payments were $\$ 95447$ (95\% Cl \$89925 to $\$ 100974)$ higher for men than for women. In a second conservative scenario, we supposed that all payments from alternative payment plan went to women. Using this assumption, physician payments were $\$ 31870$ (95\% Cl \$25089 to \$38660) higher for men than for women $(p<0.001)$.

\section{Interpretation}

Our results show a gender pay gap in physician fee-for-service claims in Ontario. We found that women had lower annual claims than men in 2017 , claiming $74 \%$ of what men claimed overall when accounting for rurality and years in practice. The difference in claims was present within almost every specialty and persisted in a sensitivity analysis that accounted for missing payments from alternative payment plans in our primary data source.

Our results are comparable to those of similar studies that have evaluated physician salaries in multiple jurisdictions. ${ }^{2-6,28-30}$ Studies evaluating specific subgroups of physicians have found sex- and gender-based salary discrepancies among research, academic and clinical physician groups. ${ }^{2,7,9,31,32}$ Similar to our findings, previous studies found that female physicians earned less than male physicians at the start of their careers, and that the income difference grew with time. ${ }^{10,33,34} \mathrm{~A}$ retrospective analysis of physician income in Ontario from 1992 to 2013 found a composite-adjusted, female-to-male, annual median income ratio of 0.77 , which was present in most subspecialties. ${ }^{35}$ Another study of primary care physicians in British Columbia found that female physicians made $36 \%$ less than male physicians in similar practice environments. ${ }^{36}$ A study of surgeons in Ontario found that female surgeons tended to earn less per hour spent operating than male physicians. ${ }^{14} \mathrm{~A}$ recent study in Ontario showed that females were less represented in the highest paying specialties, and that payments to female physicians were lower than payments to male physicians across most specialties; however, unlike our analysis, this study did not adjust for confounding factors and excluded certain groups of physicians. ${ }^{37}$ Our findings among physicians in Ontario are also similar to the broader job market. Women tend to make less than men in a wide variety of careers and the gender pay gap tends to widen with time..$^{25,38}$

Previous analyses have suggested that women physicians are more likely to work part-time than men physicians. ${ }^{36,39-41}$ However, studies that controlled for differences in work hours found that the number of hours worked did not fully account for the magnitude of the gender pay gap. ${ }^{14}$ In addition, the Canadian Medical Association's national physician survey found only a small difference in hours worked between the binary sexes. ${ }^{42}$ Other experts have suggested that female physicians are encouraged to enter lower-paying specialties, and 


\section{Table 2: Multivariate linear model of total annual claims, adjusted for covariates}

\begin{tabular}{|c|c|c|}
\hline Characteristic & $\begin{array}{l}\text { Difference in mean total annual } \\
\text { claims, } \$(95 \% \mathrm{Cl})\end{array}$ & $p$ value $^{\star}$ \\
\hline Gender (men v. women) & 95172 (89 925 to 100974$)$ & $<0.001$ \\
\hline Location of practice (rural v. urban) & -79797 (-93937 to -65734$)$ & $<0.001$ \\
\hline \multicolumn{3}{|l|}{ Years in practice } \\
\hline $0-5$ & & Ref. \\
\hline $6-10$ & 49185 (41 070 to 57731$)$ & $<0.001$ \\
\hline $11-15$ & 63528 (54 605 to 72964$)$ & $<0.001$ \\
\hline $16-20$ & 50461 (40 134 to 60960$)$ & $<0.001$ \\
\hline $21-25$ & 38283 (27 121 to 49858$)$ & $<0.001$ \\
\hline $26-30$ & 20676 (10 960 to 30403 ) & $<0.001$ \\
\hline$>30$ & $-38190(-46234$ to -30230$)$ & $<0.001$ \\
\hline
\end{tabular}

Table 3: Absolute and relative difference in adjusted total annual claims, adjusted for covariates within each specialty group

\begin{tabular}{|c|c|c|c|}
\hline \multirow[b]{2}{*}{ Specialty } & \multicolumn{2}{|c|}{ Difference in total annual claims between men and women* } & \multirow[b]{2}{*}{$p$ value } \\
\hline & $\begin{array}{l}\text { Absolute difference, } \$ \\
\qquad(95 \% \mathrm{CI})\end{array}$ & $\begin{array}{l}\text { Payments to women as a } \\
\text { percentage of payments to } \\
\text { men, } \%(95 \% \mathrm{CI})\end{array}$ & \\
\hline Ophthalmology & 328061 (204 327 to 451796 ) & 59 (30 to 88$)$ & $<0.001$ \\
\hline Cardiology & 257459 (185 579 to 329339$)$ & 61 (29 to 93) & $<0.001$ \\
\hline Diagnostic radiology & 182785 (133 319 to 232251 ) & 64 (32 to 96$)$ & $<0.001$ \\
\hline Orthopedic surgery & 178076 (108 451 to 247702 ) & 52 (32 to 71$)$ & $<0.001$ \\
\hline Medical subspecialty & 153546 (129 812 to 177281$)$ & 58 (42 to 74$)$ & $<0.001$ \\
\hline Surgical subspecialty & 138806 (91 439 to 186173 ) & 72 (53 to 90$)$ & $<0.001$ \\
\hline General surgery & 125177 (86 482 to 163872 ) & 66 (55 to 77 ) & $<0.001$ \\
\hline Anesthesiology & 101450 (77 700 to 125201$)$ & 72 (58 to 87 ) & $<0.001$ \\
\hline Pediatrics & 86110 (62 601 to 109619$)$ & 66 (39 to 93) & $<0.001$ \\
\hline Neurology & 81103 (40 343 to 121863 ) & 71 (63 to 80$)$ & $<0.001$ \\
\hline Internal medicine & 80124 (53 371 to 106876 ) & 77 (63 to 91$)$ & $<0.001$ \\
\hline Family and general practice & 72767 (66 883 to 78650$)$ & 57 (55 to 60) & $<0.001$ \\
\hline Emergency medicine & 65970 (-5325 to 137264$)$ & 46 (11 to 124$)$ & 0.7 \\
\hline Obstetrics and gynecology & 62167 (29 274 to 95060$)$ & 83 (69 to 97 ) & 0.003 \\
\hline Psychiatry & 58803 (45 772 to 71833 ) & 76 (65 to 86$)$ & $<0.001$ \\
\hline
\end{tabular}

male physicians are more likely to enter higher-paying, procedural specialties. ${ }^{43,44}$ Consistent with this research, representation of residency applicants by sex has been shown to vary widely across specialties in Canada. ${ }^{45}$ Indeed, we did find a statistically significant difference between the ratio of women in pediatrics and the baseline ratio in our cohort; in contrast, the ratio of men was higher in all surgical subspecialties compared with the cohort baseline. However, we found that women were paid less than men in nearly every specialty. Other researchers have suggested that complex systemic biases exist during training and in practice that contribute to the gender pay gap., ${ }^{732,46-53}$ The reasons underlying the discrepancy in payments that we observed are likely complex and multifactorial, and should be a focus of further research. 


\section{Limitations}

We were unable to control for important covariates that were unavailable for our analysis, such as the number of hours worked or the types of fee codes submitted by women and men. We were able to capture only payments made to physicians through the fee-for-service system. Although about $30 \%$ of physician payments in Ontario are made through an alternative payment plan, we were unable to directly characterize these payments. ${ }^{16}$ To attempt to account for this, we conducted a sensitivity analysis in which we estimated the payments missing from our first data set and allocated all missing payments to women physicians. We recognize that this analysis may not reflect the true gender pay gap, but it does show that the gender pay gap persists and is still substantial even in a conservative scenario where all payments from alternative payment plans went to women. We cannot know what portion of these payments truly went to women during our study period. However, a survey of physicians in Calgary found that physicians reimbursed entirely through an alternative payment plan were $37 \%$ more likely to be women. ${ }^{54}$ This suggests that, although we were unable to characterize payments from alternative payment plans in our main analysis, this does not change our main conclusion that a substantial gender pay gap exists in most specialties. It is noteworthy that emergency medicine physicians are more likely to be compensated through an alternative payment plan than a fee-for-service model. This may account for the larger confidence intervals seen for emergency medicine physicians in our linear regression model, which relies only on fee-for-service billings. We relied on gender data self-reported by physicians when applying for registration with the CPSO. In recent years, this registration form included 3 options (male, female and nonbinary). Although the CPSO asks physicians to report their gender during registration, the application form uses terminology relating to sex (male and female). However, the CPSO's general bylaws state that the registry contains information on physician gender. ${ }^{20}$ In our study, we have taken the position that the intent of the CPSO is to collect physician gender, and we have used terminology relating to gender. Nonetheless the incongruent terminology used by the CPSO poses a limitation to our study. We were not able to account for physician overhead costs, as this can vary across specialties and jurisdictions and is not consistently reported. ${ }^{55}$ Finally, we were not able to account for physician consulting income, which can be substantial, but is inconsistently reported.

\section{Conclusion}

We evaluated fee-for-service payments to Ontario physicians in 2017 and found that adjusted physician payments to women were $74 \%$ of payments to men. Payments to women were lower than to men in nearly all specialties. Our study was limited by our inability to control for important factors, such as hours worked. Future work should attempt to collect more detailed information for each physician to better describe the causes of the gender pay gap. Despite this, our results provide a cross-sectional analysis of physician payments in Ontario that promotes transparency and has implications for individual physicians and physician advocacy groups.

\section{References}

1. Ly DP, Seabury SA, Jena AB. Differences in incomes of physicians in the United States by race and sex: observational study. BMJ 2016;353:i2923.

2. Read S, Butkus R, Weissman A. Compensation disparities by gender in internal medicine. Ann Intern Med 2018;169:658-61.

3. Weaver AC, Wetterneck TB, Whelan CT. A matter of priorities? Exploring the persistent gender pay gap in hospital medicine. J Hosp Med 2015;10:486-90.

4. Wiler JL, Rounds K, McGowan B, et al. Continuation of gender disparities in pay among academic emergency medicine physicians. Acad Emerg Med 2019;26:286-92.

5. Spencer ES, Deal AM, Pruthi NR, et al. Gender differences in compensation, job satisfaction and other practice patterns in urology. J Urol 2016;195:450-5.

6. Frintner MP, Sisk B, Byrne BJ, et al. Gender differences in earnings of early- and midcareer pediatricians. Pediatrics 2019;144:e20183955.

7. Jena $A B$, Olenski AR, Blumenthal DM. Sex differences in physician salary in US public medical schools. JAMA Intern Med 2016;176:1294-304.

8. Mensah M, Beeler W, Rotenstein L, et al. Sex differences in salaries of department chairs at public medical schools. JAMA Intern Med 2020;180:789-92.

9. Connolly S, Holdcroft A. The pay gap for women in medicine and academic medicine: an analysis of the WAM database. London (UK): British Medical Association; 2009.

10. Lo Sasso AT, Armstrong D, Forte G. Differences in starting pay for male and female physicians persist; explanations for the gender gap remain elusive. Health Aff (Millwood) 2020;39:256-63.

11. Rao AD, Nicholas SE, Kachniarz B. Association of a simulated institutional gender equity initiative with gender-based disparities in medical school faculty salaries and promotions. JAMA Netw Open 2018;1:e186054.

12. Jagsi R, Griffith KA, Stewart A, et al. Gender differences in the salaries of physician researchers. JAMA 2012;307:2410-7.

13. Apaydin EA, Chen PGC, Friedberg MW. Differences in physician income by gender in a multiregion survey. J Gen Intern Med 2018;33:1574-81.

14. Dossa F, Simpson AN, Sutradhar R. Sex-based disparities in the hourly earnings of surgeons in the fee-for-service system in Ontario, Canada. JAMA Surg 2019;154:1134-42.

15. Report to Council: understanding gender pay gaps among Ontario physicians. Toronto: Ontario Medical Association; 2020.

16. Henry DA, Schultz SE, Glazier RH, et al. Payments to Ontario physicians from Ministry of Health and Long-Term Care sources, 1992/93 to 2009/10. Toronto: ICES; 2012.

17. Search our database of Ontario doctors. Toronto Star. Available: https://www. thestar.com/ontario-doctor-list (accessed 2021 Jan. 13).

18. Doctor search. Toronto: College of Physicians and Surgeons of Ontario. Available: https://doctors.cpso.on.ca/ (accessed 2021 Jan. 13).

19. National Physician Database metadata. Canadian Institute for Health Information. Available: https://www.cihi.ca/en/national-physician-database-metadata (accessed 2021 Jan. 13).

20. General by-law. College of Physicians and Surgeons of Ontario. Available: https://www.cpso.on.ca/admin/CPSO/media/Documents/about-us/legislation -bylaws/general-bylaw.pdf (accessed 2021 Jan. 13).

21. Forward sortation area: definition. Ottawa: Office of the Superintendent of Bankruptcy Canada; modified May 29. Available: https://www.ic.gc.ca/eic/site/ bsf-osb.nsf/eng/br03396.html (accessed 2021 May 25).

22. Physician reports. Hamilton (ON): Ontario Physician Human Resources Data Centre (OPHRDC), McMaster University. Available: http://www.ophrdc.org/ physician-reports/\#pio2017 (accessed 2021 Jan. 13)

23. Austin PC. An introduction to propensity score methods for reducing the effects of confounding in observational studies. Multivariate Behav Res 2011;46:399-424.

24. Lewiss RE, Silver JK, Bernstein CA, et al. Is academic medicine making midcareer women physicians invisible? J Womens Health (Larchmt) 2020;29: 187-92.

25. Schneer JA, Reitman F. The importance of gender in mid-career: a longitudinal study of MBAs. J Organ Behav 1994;15:199-207.

26. Weeks WB, Wallace AE. Rural-urban differences in primary care physicians practice patterns, characteristics, and incomes. J Rural Health 2008;24:161-70.

27. Chen S-Y, Feng Z, Yi X. A general introduction to adjustment for multiple comparisons. J Thorac Dis 2017;9:1725-9.

28. Glauser W. Why are women still earning less than men in medicine? CMAJ 2018;190:E664-5. 
29. Roy B. Gender pay gaps in medicine: moving from explanations to action. J Gen Intern Med 2018;33:1413-4.

30. Buys YM, Canizares M, Felfeli T, et al. Influence of age, sex, and generation on physician payments and clinical activity in Ontario, Canada: an age-periodcohort analysis. Am J Ophthalmol 2019;197:23-35.

31. Butkus R, Serchen J, Moyer DV, et al. Achieving gender equity in physician compensation and career advancement: a position paper of the American College of Physicians. Ann Intern Med 2018;168:721-3.

32. Mascarenhas A, Moore JE, Tricco AC, et al. Perceptions and experiences of a gender gap at a Canadian research institute and potential strategies to mitigate this gap: a sequential mixed-methods study. CMAJ Open 2017;5: E144-51.

33. Lo Sasso AT, Richards MR, Chou C-F, et al. The $\$ 16,819$ pay gap for newly trained physicians: the unexplained trend of men earning more than women. Health Aff (Millwood) 2011;30:193-201.

34. Esteves-Sorenson C, Snyder J. The gender earnings gap for physicians and its increase over time. Econ Lett 2012;116:37-41.

35. Cohen M, Ferrier BM, Woodward CA, et al. Gender differences in practice patterns of Ontario family physicians (McMaster medical graduates). J Am Med Womens Assoc (1972) 1991;46:49-54.

36. Hedden L, Barer ML, McGrail K. In British Columbia, the supply of primary care physicians grew, but their rate of clinical activity declined. Health Aff (Millwood) 2017;36:1904-11.

37. Cohen M, Kiran T. Closing the gender pay gap in Canadian medicine. CMAJ 2020;192:E1011-7.

38. EXECUTIVE SUMMARY Overall Gender Pay Gap Gender Pay Gap by Race Opportunity Gap Pay Gap by Education Pay Equity Guide for HR Methodology. [copyeditor: please have author confirm reference.]

39. Hedden L, Barer ML, Cardiff K, et al. The implications of the feminization of the primary care physician workforce on service supply: a systematic review. Hum Resour Health 2014;12:32.

40. Gravelle H, Hole AR. The work hours of GPs: survey of English GPs. Br J Gen Pract 2007;57:96-100.

41. Frank E, Zhao Z, Sen S. Gender disparities in work and parental status among early career physicians. JAMA Netw Open 2019;2:e198340.
42. CMA National Physician Health Survey: a national snapshot. Ottawa: Canadian Medical Associtation (CMA); 2018.

43. O'Connor MI. Medical school experiences shape women students' interest in orthopaedic surgery. Clin Orthop Relat Res 2016;474:1967-72.

44. Hill E, Bowman K, Stalmeijer R, et al. You've got to know the rules to play the game: how medical students negotiate the hidden curriculum of surgical careers. Med Educ 2014;48:884-94.

45. Lorello GR, Silver JK, Moineau G, et al. Trends in representation of female applicants and matriculants in Canadian residency programs across specialties, 1995 to 2019. JAMA Netw Open 2020;3:e2027938.

46. Kwon E, Adams TL. Choosing a specialty: intersections of gender and race among Asian and white women medical students in Ontario. Can Ethn Stud 2018;50:49-68.

47. Carnes M, Morrissey C, Geller SE. Women's health and women's leadership in academic medicine: Hitting the same glass ceiling? J Womens Health (Larchmt) 2008;17:1453-62

48. Downs JA, Reif LK, Hokororo A, et al. Increasing women in leadership in global health. Acad Med 2014;89:1103-7.

49. Zhuge Y, Kaufman J, Simeone DM, et al. Is there still a glass ceiling for women in academic surgery? Ann Surg 2011;253:637-43.

50. Ruzycki SM, Freeman G, Bharwani A. Association of physician characteristics with perceptions and experiences of gender equity in an academic internal medicine department. JAMA Netw Open 2019;2:e1915165.

51. Hoops HE, Brasel KJ, Dewey E. Analysis of gender-based differences in surgery faculty compensation, promotion, and retention: establishing equity. Ann Surg 2018;268:479-87.

52. Gray K, Neville A, Kaji AH. Career goals, salary expectations, and salary negotiation among male and female general surgery residents. JAMA Surg 2019;154:1023-9.

53. Bowles HR, Babcock L, Lai L. Social incentives for gender differences in the propensity to initiate negotiations: sometimes it does hurt to ask. Organ Behav Hum Decis Process 2007;103:84-103.

54. Cunningham CT, Jetté N, Li B, et al. Effect of physician specialist alternative payment plans on administrative health data in Calgary: a validation study. CMAJ Open 2015;3:E406-12.

55. National Physician Database Data Release, 2018-2019: methodology notes. Ottawa: Canadian Institute for Health Information; 2020.
Competing interests: Alana Flexman reports membership on the diversity, equity and inclusion committees of the Canadian Anesthesiologists' Society and Vancouver Coastal Health. Tara Kiran reports payments from the Ontario Medical Association, the Ontario College of Family Physicians, the Nova Scotia Health Authority, Doctors of BC and the Osgood Hall Law School, outside the submitted work. No other competing interests were declared.

This article has been peer reviewed.

Affiliations: Division of Neurosurgery (Merali, Malhotra, Balas), Department of Surgery, and Department of Anesthesiology and Pain Medicine (Lorello), University of Toronto; Department of Anesthesia and Pain Medicine (Lorello), Toronto Western Hospital - University Health Network, Toronto, Ont.; Department of Anesthesiology, Pharmacology, and Therapeutics (Flexman), University of British Columbia, Vancouver, BC; Department of Family and Community Medicine (Kiran), St. Michael's Hospital, University of Toronto; Institute of Health Policy, Management and Evaluation (Kiran, Witiw), University of Toronto; Division of Neurosurgery (Witiw), Department of Surgery, University of Toronto, St Michael's Hospital, Toronto, Ont.

Contributors: Zamir Merali, Armaan Malhotra, Michael Balas and Christopher Witiw contributed to the conception and design of the work. All authors contributed to the acquisition, analysis, and interpre- tation of data. Zamir Merali, Armaan Malhotra, Michael Balas and Christopher Witiw drafted the manuscript, and all authors revised it critically for important intellectual content. All of the authors gave final approval of the version to be published and agreed to be accountable for all aspects of the work.

Content licence: This is an Open Access article distributed in accordance with the terms of the Creative Commons Attribution (CC BY-NC-ND 4.0) licence, which permits use, distribution and reproduction in any medium, provided that the original publication is properly cited, the use is noncommercial (i.e., research or educational use), and no modifications or adaptations are made. See: https://creativecommons.org/licenses/by-nc-nd/4.0/

Funding: The authors received no financial support for the research, authorship or publication of this article. Tara Kiran is the Fidani Chair in Improvement and Innovation at the University of Toronto and supported as a Clinician Scientist by the Department of Family and Community Medicine at St. Michael's Hospital and the University of Toronto.

Data sharing: All data sources used in this study are publicly available and are available from online sources. The protocol and statistical analysis plan used in this study are available upon request.

Accepted: Aug. 4, 2021

Correspondence to: Christopher Witiw, christopher.witiw@unityhealth.to 